E. Solar Correa.

\title{
UN GRAN POETA EN PROSA
}

\section{Alonso DE OVAlle (1601-1651)}

( $\mathrm{N}$ las páginas anteriores (1) hemos procurado enfrentar al P. Alonso de Ovalle con las cosas de Chile - con los moradores, con el paisaje-; en las que siguen vamos, por el contrario, a intentar aislarlo. Querríamos extraerlo de la obra y exhibir el interesantísimo tipo humano que tras ella se adivina. ¿Quién era, cómo era el hombre que tres siglos ha plantó el primer árbol de nuestra frondosa selva histórica? Los estudios biográficos nos lo muestran en la periferia, y acaso lo más atrayente está en su personalidad íntima.

Un examen atento de la amable Relación induce a pensar que sus atributos literarios derivan esencialmente de la viveza con que se representaba, con que revivía las percepciones y reacciones sensoriales, y particularmente las de la vista. Ovalle fué-ya se habrá advertido por los trozos que quedan citados-un

(1) Véase el número anterior de Atenea. 
prodigioso visual; para él recordar es volver a ver. Tan viva es esta ilusión óptica que, cuando describe, usa con frecuencia el presente:

Vamos por aquellos montes pisando nubes.... Aquí se ven partir juntos estos arroyos.... A cada paso brotan y saltan fuentes de aguas frescas y cristalinas....

Alguien podría pensar que se trata de un mero artificio retórico; pero no: todo en él es espontaneidad. Escribe calamo currente. Mana su prosa como un agua limpia y clara que avanzase entre yerbas, sin obstáculos. El aliño, el retoque están ausentes. No son raras las repeticiones de palabras, los pleonasmos, y hasta en ocasiones la idea del autor, dentro de una misma frase, parece cambiar de rumbo, con lo que la cláusula queda sin un orden lógico estricto. Nada indica el menor artificio, y no habría por qué suponerlo en el uso de tales o cuales formas del verbo.

Decíamos que la vista era en nuestro escritor el sentido preponderante: de ahí su amor de la naturaleza como espectáculo, su gusto por la descripción, su estilo plástico y coloreado. Y ese poder visual, que al ejercitarse se transforma en goce, lo lleva a trepar lugares empinados desde donde se pueda atalayar el paisaje. Unas veces lo encontramos sobre las crestas andinas persiguiendo con los ojos el espumante raudal que corre en lo hondo de algún barranco, "aunque con pavor, porque pone grima tan inmensa altura»; otras en lo más alto de algún campanario, en el de San Francisco por ejemplo, desde donde se goza por todos lados de bellísimas vistas, que son de grandísimo recreo $y$ alegría; ya es el Huelén que le «sirve como de atalaya» para espaciar la mirada por todo el llano, «hermoseando con alegres vegas y vistosos prados en unas partes, y en otras de espesos montes de espinales», ya las faldas boscosas de los contrafuertes más próxi- 
mos: «no es la menor parte del gusto y recreo, las alegres vistas que se gozan de lo alto a la salida de este bosque», dice al describir una de las quebradas de los alrededores de Santiago

Descúbrense por unas partes-agrega-grandes manchas de flores amarillas que cubren la tierra...; en otras, de blancas, azules y moradas; allí se ven los prados verdes, y cruzar por entre ellos, los arroyos y acequias del río Mapocho, el cual todo se da a una vista... Vense, finalmente, muchos lugares edificados (que allá llamamos chacras, con sus iglesias y son como aldeas o caseríos) y en medio de todos, la ciudad de Santiago, que es la cabeza del reino, y con estar distante de allí dos leguas, sin embargo, por ser el aire tan puro, en los días claros se van muy distintamente sus torres, y tal vez se oyen tamibién las campanas.

Su ojo avizor podría compararse a una cámara fotográfica de extraordinaria profundidad focal. Los objetos, vistos a gran distancia, no aparecen a su pupila imprecisos, esfumados, sino empequeñecidos, pero conservando sus líneas netas, firmes. A los hombres los percibe como pigmeos; los grupos de palmas que crecen en los montes, «mirándolos de lejos, [le] parecen almácigo puesto a mano»; y los grandes ríos, diminutos arroyuelos.

Yo he llegado al borde de esta puente-la Puente del Inca-, y mirando para abajo, no sólo no oí rumor ninguno, pero pareció de allí todo el río un pequeño arroyo....

Acaso por esa misma clarividencia y como temeroso de que ella le engañe, recurre a veces al oído para proporcionar la sensación de la distancia:

es fuerza que pasando por ella (por una estrecha abertura de la montaña) todo junto un río tan caudaloso, y de tanto ímpetu y corriente, haga muy grande ruido al pasar por esta estrechura; de donde se sigue que el no salir arriba el ruido de tanta agua, es por estar sumamente distante.... 
(Perdónesenos el número excesivo de citas, pero Ovalle es un autor casi desconocido y nuestras afirmaciones, sin el apoyo constante del texto, podrían creerse antojadizas.)

La deleitosa contemplación de la naturaleza no está en el jesuíta reservada únicamente a los amplios panoramas. También ama el pequeño detalle, se detiene ante él, y lo examina con pueril asombro.

Una vez en particular-escribe en una de sus páginas- me acuerdo que yendo camino vi tanta diversidad de estas flores [silvestres], unas encarnadas, otras azules, amarillas, coloradas, pajizas, moradas columbinas y de otros varios colores, que poniéndome a contarlas, movido de la admiración de tanta variedad como la que se veía, conté hasta cuarenta y dos especies....

Nada, sin embargo, le procura mayor delectación que el espectáculo de las aguas. Ya hemos podido percatarnos de la amorosa complacencia con que las describe al hablar de la Cordillera. Léase una segunda vez ese párrafo admirable. En las letras españolas, y acaso en las europeas, nadie expresó antes y mejor su belleza cambiante y multiforme.

Definir a Alonso de Ovalle simplemente como un visual sería dar sólo un aspecto de su privilegiada organización sensorial. La constante eufonía del estilo, desde luego, hace sospechar una desarrollada sensibilidad auditiva, que en Chile, durante el siglo XVII, tuvo sin duda muy pocas ocasiones de ejercitarse si no fué escuchando el cantar de las aves, cuya \&dulce música y armonía hacen mayor y más apacible el entretenimiento» de sus campestres solaces. Alude algunas veces a los coros de iglesia y a las charangas de los negros, pero aquello debía ser algo tan elemental que no suscita en él entusiasmo alguno. La música de los pájaros, en cambio, parece cautivarle. 
Formando-dice-unos el bajo, otros el tenor y otros el contralto y tiple, hacen una armonía del cielo, particularmente en verano, cuando se recogen a sestear a la sombra de los árboles.

Las sensaciones del olfato éranle, sin duda, más asequibles.

Al recordar, desde Roma, las flores espontáneas de nuestros valles se refiere con manifiesto placer a su perfume:

son generalmente muy olorosas-apunta-, y sacan de ellas las aguas que llaman de ángeles, por la suavidad de su fragancia, con la cual llenan el aire de suavísimo olor, el cual se siente más en particular cuando sale el sol y se pone....

Las yerbas campesinas también se le insinúan en el mismo idioma: «son muy aromáticas y odoríferas»... «no ayudan poco a la fragancia de los campos». En los árboles autóctonos parece atraerle más su aroma que la belleza de las líneas o del follaje.

Andando por aquellos caminos [en las inmediaciones de Concepción] topaba hermosísimas arboledas, que por uno y otro lado nos cercaban, y era el olor de sus hojas tan apacible y suave, que me parecía no serlo más el de los jazmines y violetas; bien agradable es el de los mirtos, arrayanes y laureles, de que hay también por allí grandes bosques que se crían de suyo sin artificio humano; pero, con todo eso, no llega a la delicadeza y fineza del olor que tienen otros árboles, que entre ellos se crian de varias especies, que pasando la mano por sus hojas la dejan tan olorosa como si hubieran traído guantes de olor.

Conviene advertir que la sensibilidad olfativa del P. Alonso no es un caso excepcional en la Colonia. Diríase que cada época tiene un sentido predilecto, al que se esfuerza en poner a prueba. Ahora, por ejemplo, estamos en el siglo de la actividad acústica. La música - la mala y la buena - y aun el bullicio, atraen, 
hechizan a la multitud. Como si todo el ruido de la ciudad fuera nada, en c dda esquina, rodeado de auditorio numeroso, hay un ciego majadero que toca la flauta o un mal violín, y desde cada puerta y cada ventana salen los sones metálicos de algún fonógrafo o la voz cavernosa de la radio. El único refugio de silencio que iba quedando eran las salas del cine, pero ¿cómo tolerar por más tiempo el anacronismo de un teatro mudo? $\mathrm{Y}$ de ahí el delirio con que se han acogido los destemplados ruidos del nuevo cine - parlante, cantante, sonante-, que es como decir expresión genuina de la época. El siglo XIX, por su parte, quizá pudiera definirse como un siglo ocular. Si hiciésemos una clasificación de sus escritores en orden al sentido predominante, lo probable es que los visuales se llevasen la palma, y muy lejos. Algo semejante cabe decir de los autores de la Colonia, pero con respecto al olfato. Este desen peñó, indudablemente, un papel importante en la vidá de nuestros abuelos. La mayor o menor solemnidad de las fiestas religiosas, que eran las grandes fiestas de la época, parecía evaluarse por la suma y calidad de los olores. Ovalle, exaltando la magnificencia con que se celebraba el Corpus Christi en la Catedral de Santiago, cuenta que, durante ocho días, estaba "hecha la iglesia una poma de olor, cuya fragancia se siente a mucha distancia antes de llegar a ella». En otro lugar, describe con lujo de detalles la procesión y fiesta del Tránsito; se ve que las palabras le sobran para expresar sus diversas sensaciones.... Pero llega un momento en que no las encuentra:

¿qué diré-se pregunta-de los olores, flores artificiales (1). pomas, cazoletas, pebetes y pebeteros?

(1) Las flores artificiales a que aquí se alude eran, seguramente, perfumadas. No se explicaría de otra manera el que el autor las equipare a las pomas, pebeteros, cazoletas, etc.

Atenea.-2 
He aquí una confesión tácita pero expresiva de la intensidad que este género de sensaciones alcanza en él. Su lenguaje, particularmente rico en vocablos adecuados al objeto, se declara vencido ante la realidad de ellas. No todo, sin embargo, era fiesta para la exquisitez olfativa del jesuíta. Había por entonces en Chile unos negros llamados bozales, a quienes era preciso instruir y confesar, y tenemos motivos para suponer que el ejercicio del sagrado ministerio debía complicársele, en este caso, con problemas bien poco espirituales.

Es insufrible-dice-el mal olor que echan de sí, y encalabria las cabezas y obliga muchas veces a detener el resuello...

Una obra de carácter narrativo, como la del P. Ovalle, no se presta, ciertamente, al estudio que vamos intentando, pero bajo la objetividad del asunto y sin que el autor se lo proponga, transparéntase clara y distinta su fisonomía espiritual y fisiológica. Hasta adivinamos en él una fineza extremada de la sensación táctil, fenómeno que, como nadie ignora, rara vez se presenta en los visuales, cuanto suele ser frecuente en los que carecen de la vista. Las descripciones de arroyos y manantiales que tanto abundan en la Histórica relación van a servirnos para rastrear este nuevo aspecto. El agua para él no sólo es «clara y cristalina como un sol», sino también "suave y blanda» (1). En los aledaños de Santiago descubre una vertiente «muy copiosa, de muy suaves y delicadas aguas». Otras se le antojan «regaladísimas y suavísimas». A su paso por la Cordillera hunde las manos con fruición en una clara fuente andina y muchos años después recuerda todavía que antes de terminar «un solo credo» el frescor de nieve le obligó a retirarlas. El agua provoca en su epidermis una especie de voluptuosidad. Tan

(1) ¿Es el agua de esta fuente notablemente suave y blanda..., 
ostensible es dicha circunstancia que, cuando leíamos su libro, en nota marginal escribimos: « ¡Cómo ama este hombre las aguas! No contento con deleitar su vista en ellas, parece gozarse en palparlas, en acariciarlas.... » Y no fué pequeña nuestra sorpresa al posar poco después los ojos en las líneas que siguen:

Aun sin beberse-el autor habla de las aguas de Bucalemu, propiedad entonces de la Compañía de Jesús-, aun sin beberse se conoce en el tacto su nobleza, porque su blandura y suavidad es como de mantequillas, y así ablandan y molifican las manos...

La tímida pero tiranizante conjetura del escoliasta era una realidad perfectamente comprobable. Ovalle palpaba, acariciaba las aguas. Quizá hubiera podido decir con Renée Vivien (1):

Je comprends mieux, en les frôlant, les choses belles;

je partage leur vie intense en les touchant;

c'est alors que je sais ce qu'elles ont en elles

de noble, de très doux et de pareil au chant.

La obra, en general, respira la gozosa bienandanza de hombre que, despreocupado de graves o ásperos problemas y sin que lo atice la ambición, se deleita viviendo, mirando, paladeando cuanto le rodea. Diríase que la vida es una noble y sabrosa fiesta para este goloso de sensaciones. Hasta llega a realizar, a veces, como para multiplicarlas - y de manera espontáneaese trueque o transposición sensorial, caro a Baudelaire, que nos parecía una de las más audaces novedades de la sensibilidad moderna. El agua la palpa a más de mirarla y gustarla, extendiendo así al tacto la sensa-

(1) La sensibilidad epidérmica, a juicio de ciertos críticos franceses, habría sido incorporada a la literatura sólo en los últimos tiempos. La novedad se atribuye a Renée Vivien, la bella y sutil poetisa lésbica. Posteriormente otros escritores han seguido su ejemplo, y en particular algunos de su mismo sexo, la Condesa de Noailles, Gérard d'Houville, Colette. 
ción de ella. El olfato le habla de belleza del mismo modo que al poeta de las Flores del mal le hablaba de colores y sonidos: "es de tan lindo olor y tan preciosa esta madera». ¿Tan lindo olor! Curiosa suerte la de esta expresión.... Huérfana, perdida en el fárrago de un libro viejo, ha esperado siglos antes que las Correspondances baudelerianas vinieran a legitimar el insólito connubio que ella propone, de la belleza y el perfume

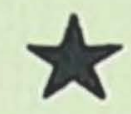

Pues bien. Aquel organis'mo tan maravillosamente condicionado para el placer y para el arte quizá fué un constante tormento en el jesuíta. El goce de los sentidos a que su natural le inclinaba, constituía - debió constituir, a su juicio-un escollo en el camino de santidad que se había propuesto seguir desde la infancia. Súmese, por una parte, a la vehemencia de su temperamento-ya veremos que era un hombre apasionado - el perpetuo y tentador halago de los sentidos, súmese, por la otra, su fe profunda y su anhelo de ascensión espiritual: imaginemos luego estos impulsos antagónicos combatiéndose en lo íntimo de su conciencia. La tragedia interior surge inevitable. Y aquí podría estar el secreto de aquellas noches insomnes en que el buen $\mathrm{P}$. Alonso se entregaba a una oración desesperada, y el origen y explicación de las torturas cotidianas a que sometía su carne y del furor con que a veces la disciplinaba hasta "causar espanto" en sus vecinos de celda (1). ¿No sería todo una especie

(1) Solía, a veces, según referían algunos que estaban cerca de él, pasar hasta tres noches sin dormir orando continuamente; sus mortificaciones eran excesivas, su alimentación escasa, y dormía en una cama que no tenía colchón ni sábanas, y a veces se azotaba tan cruelmente que causaba espanto a los que lo oían.» Medina, Hist de la Lit. Colonial de Chile, t. II, pág. 122. 
de compensación ofrecida al cielo por los deleites terrenos que esa misma carne le proporcionaba con sólo abrir los ojos para mirar? Ovalle aun por la senda de la mortificación llega al refinamiento. Si el olfato le da placer, escoge para sí, como tarea predilecta, la instrucción moral y religiosa de los esclavos de color que, como se ha visto, no solían oler a gratas ambrosías (1).

Hombre del sigo XVII -el siglo de las violentas pasiones, el siglo de la Quintrala -, Alonso de Ovalle poseía un alma férvidamente apasionada.

Como su voz salía de aquel corazón abrasado-escribe Cassani-encendía en devoción a cuantos le oían (2).

La evocación de la patria lejana, las mil sensaciones con que otrora ella pobló su fantasía, constantemente renovadas, redivivas, convertidas en bullentes y atractivas imágenes, encienden su alma en cálido afecto, y ese fuego interior acaba por quemar la misma lámpara en que arde.

En el viaje que hizo de aquellas partes a España-son sus palabras-no pude ver en todo el camino aquellos horizontes de Chile, sino otros muy diferentes, cargados, melancólicos y tristes....

Ahora iba a volver a verlos. Desde la borda del perezoso velero en que regresa de Europa, sus miradas se han dirigido muchas veces hacia el sur, ansiosas, escudriñadoras. Violento, al fin, porque le parece que la nave no avanza, deja en ésta a sus compañeros y desembarca en Paita, resuelto a venirse por tierra.

(1) A su regreso de Córdoba (Tucumán), donde había hecho un noviciado de ocho años, y después de ordenarse en Santiago, tomó a su cargo la instrucción de los esclavos negros, tarea a la cual consagró sus mejores esfuerzos mientras estuvo en Chile.

(2) Cassani: Glorias del segundo siglo de la Compañía de Jesús, t. II. pág. 221 y sigtes. No está de más agregar aquí que la fama del P. Ovalle en su carácter de orador sagrado transpuso las fronteras. Aunque sus sermones no se han conservado, debería, en justicia, considerársele como el iniciador de la elocuencia del púlpito en Chile. 
Cabalga varios días y, cruzando desiertos, afrontando los soles del trópico, sin agua, sin provisiones suficientes, llega extenuado a la capital de los virreyes; y allí, aquellos ojos, ávidos de escrutar los patrios horizontes, los cielos «serenos, dorados y bellos», se abren para siempre ante lo inescrutable (1).

Hay en este final algo de profundamente desolador. La pluma se siente como cohibida al querer proseguir en su análisis un poco implacable. Pero la figura del P. Alonso no se nos ha mostrado todavía en todos sus contornos. El recuerdo desconcertante de su muerte ha surgido aquí únicamente como una comprobación de su temperamento pasional. Cuando se piensa en éste $\mathrm{y}$ en las tempestuosas tragedias de que tal vez fué teatro su espíritu, sorprende la serenidad y dulcedumbre que emana de sus páginas. Existen, ciertamente, otros factores psíquicos que explican la antinomia, y son la fe y la voluntad, una fe en plenitud y una voluntad de acero. Así como ambas de consuno fueron capaces de transformar el desagrado físico en emoción afectuosa - Ovalle amaba entrañablemente a sus negros-, hubieron de tener el poder necesario para trocar la tormenta interior en alegría y paz del espíritu. Aun en la prosa del jesuíta se trasluce el señorío de sí mismo. No es fácil, en efecto, encontrar en ella exclamaciones $\mathbf{u}$ otras figuras patéticas que delaten la pasión o el entusiasmo, y por todo el libro circulan, contenidos, el entusiasmo y la pasión.

Martí dijo algún día de José María de Heredia-

el cubano-, al compararlo con la naturaleza americana: «es volcánico como sus entrañas, y sereno como sus alturas». Lab ella frase, ahora que pensamos en Alonso de Ovalle, ha tornado, inesperada, a nuestra memoria. (Concluirá.)

(1) Murio en Lima el 11 de Mayo de 1651, a la edad de cincuenta años. Una fiebre maligna ocasionada por lo penoso y violento del viaje fué, según sus bi6grafos, la causa de la muerte. 